\title{
A Study on the Factors Influencing Workplace Bullying and Its Impact on Employee Stress
}

\author{
M. Rajalakshmi \\ Research Scholar, VIT Business School, VIT University, India. \\ Dr. S. Gomathi \\ Senior Professor, VIT Business School, VIT University, Vellore-632014, Tamilnadu, India \\ Email: sgomatthi@vit.ac.in, gommatthi@gmail.com
}

\section{Doi:10.5901/mjss.2015.v6n1p292}

\section{Abstract}

Workplace bullying in the twenty-first millennium is not something new, not anything unknown. Bullying has been experienced since time immemorial, but its toll is higher than ever before. Workplace bullying means harassment, threatening or a negative behaviour of an employee towards their peer employee (or) to the sub-ordinates in the organization, due to this the victim will have an effect on physically, psychologically and professional factors. There are different forms of bullying activities can be carried out in the workplace. Like, verbal bullying, nonverbal bullying, psychological bullying and the physical bullying. Merely, bullying activity in the organization resembles the power of an employee towards the other employee. This research is basically done on the factors influencing workplace bullying and its impact on employee stress.

Keywords: Workplace Bullying, Employee Stress, Factors of Workplace Bullying, Impact of Employee Stress.

\section{Introduction}

Workplace bullying, like childhood bullying, is the tendency of individuals or groups to use persistent aggressive or unreasonable behaviour against a co-worker or subordinate. Workplace bullying can include such tactics as verbal, nonverbal, psychological, physical abuse and humiliation. Bullying in the workplace is in the majority of cases reported as having been perpetrated by management and takes a wide variety of forms. Bullying can be covert or overt, may be missed by superiors or known by many throughout the organization. Negative effects are not limited to the targeted individuals, and lead to a decline in employee morale and company culture.

Workplace bullying involves the repetitive, prolonged abuse of power. Unwelcome, unreasonable, escalating behaviors are aggressively directed at one or more workers and cause humiliation, offence, intimidation and distress. It places their health, well-being, safety and career at risk, interferes with job performance and creates a toxic working environment. Workplace bullying can attack anyone, in any career, at any level, within any organization, at any time.

Workplace bullying refers to repeated, unreasonable actions of individuals (or a group) directed towards an employee (or a group of employees), which are intended to intimidate, degrade, humiliate, or undermine; or which create a risk to the health or safety of the employee(s).

\subsection{Definition}

According to Tracy, Lutgen-Sandvik, and Alberts, Workplace bullying is most often,

"A combination of tactics in which numerous types of hostile communication and behavior are used."

According to Pamela Lutgen-Sandvik,

"Persistent verbal and nonverbal aggression at work that includes personal attacks, social ostracism, and a multitude of other painful messages and hostile interactions."

\subsection{Bullying}

Norwegian researcher Dan Olweus says bullying occurs when a person is: 
'Exposed, repeatedly and over time, to negative actions on the part of one or more other persons'. He says negative actions occur 'when a person intentionally inflicts injury or discomfort upon another person, through physical contact, through words or in other ways

\subsection{Cost Of Bullying For An Organization}

Each of the individual consequences listed above can be very costly for the organization. Costs of bullying generally fall on the below categories:

- Replacing staff members that leave as a result of being bullied, cost of training new employees.

- Work effort being displaced as staff cope with bullying incidents (i.e., effort being directed away from work productivity and towards coping)

- Costs associated with investigations of ill treatment and potential legal action.

\subsection{Various Workplace Bullying Types In Organization}

- Verbal bullying

- Nonverbal bullying

- Physical bullying

- Psychological bullying

\subsection{Methods Of Bullying}

- Manipulates through seduction

- Intimidates through verbal aggression

- Uses political gamesmanship

- Plays mind games

- Disguises true intentions and emotions

1.6 Consequences Of Employer And Employee

\subsubsection{Consequences for Employers}

- Reduced efficiency, productivity and profitability, Increased absenteeism, sick leave and staff turnover.

- Poor morale, erosion of employee loyalty and commitment.

- Increased costs associated with recruitment and training.

- Potential increase to insurance and workers' compensation premiums.

\subsubsection{Consequences for Employees}

- Stress, anxiety, sleeps disturbance, and Panic attacks.

- Incapacity to work, concentration problems, loss of self-confidence and self-esteem or reduced output and performance.

- Depression or a sense of isolation. Physical injury, reduced quality of home and family life.

- Suicide.

\section{Historical Leaflets}

\section{1 leaflet related to workplace bullying and stress}

Jez Abbott, (2006) found that the trade union chiefs have recruited David Beckham in their fight against workplace bullying, discrimination and stress. Amicus teamed up with the David Beckham Academy to offer prizes for staff in print, publishing and online data that complete a union questionnaire. The workplace survey quizzes people from pre-press and 
print, to floor cleaners and warehouse staff on whether they have been bullied, harassed or stressed. Respondents are asked about promotion prospects, flexibility of working practices and whether they have done unpaid overtime. "Members face many problems in their day-to-day work and this is a new way to identify them," said assistant general secretary Tony Burke. He added that Amicus was "always looking for new ways to appeal" to workers, and coaxing them with the David Beckham Academy was a coup. Prizes include training camps for children aged eight to 15, copies of the David Beckham Skills book, the Really Bend it like Beckham DVD.

Vartia and Hyyti (2002) investigated the gender differences in facing and experiencing workplace bullying. The subjects were 773 male and 123 female prison officers. No difference was found in this respect between men and women. Female victims had been subjects of sexual harassment significantly more often than their male colleagues. The persons bullying female officers were usually co-workers, whereas men were bullied by co-workers and supervisors equally often. Bullying had similar effects on the feelings of stress, mental health, and job satisfaction of both men and women.

Jennifer et al. (2002) has undergone an investigation into employees' perceptions of social and organizational work conditions and experiences of bullying at work. The participants were Six-hundred-seventy-seven employees from five different working populations (managers, teachers, technicians, call centre operators, and engineers). After analyzing the link between the experiences of bullying and perceptions of social and organizational work conditions, Jennifer et al. (2002) identified victims and non-bullied participants, and she also indicated the existence of a new category of employee affected by the problem of bullying; bullied/non-victims. Bullied/non-victims may provide crucial insights into the ways that company practices and policies impact negatively on the whole workforce.

Sheehan (1999) has outlined some of the signs indicating bullying in the workplace as a problem within contemporary organizations. He mentioned some of the costs that organizations may be faced with if they fail to address the problem. Having identified the problem, Sheehan (1999) then suggested some solutions including legislative change and development of more co-operative workplaces. Such workplaces would deal with the problem in a problem solving, rather than punitive, framework. Development of people's emotional intelligence skills was also suggested as one way to help address the problem within such a framework.

Andy ellis (1994), paid specific attention to the British retail industry. The survey indicating that 1 in 2 UK employees have been bullied at work during their working life. Andy ellis (1994), explained that workplace bullying is not only unhealthy for those being bullied but also for the organizations which are allowing it to continue. Andy ellis (1994), also found that even many of the employers which are leading in this area by adopting anti bullying policies are allowing their line management to ignore the policy and instead provide an atmosphere of uncertainty within their organizations.

Kivimäki et al. (2002) has examined the exposure to workplace bullying as a risk factor for cardiovascular disease and depression in employees. The respondents were 5432 hospital employees in which, 601 participants are men and 4831 are women, aged 18-63 years. A strong association between workplace bullying and subsequent stress suggests that bullying is an etiological factor for mental health problems. The victims of bullying also seem to be at greater risk of cardiovascular disease, but this risk may partly be attributable to overweight.

Lyn Quine (1998) determined the prevalence of workplace bullying in an NHS community trust; and he examined the association between bullying and occupational health outcomes; Lyn Quine (1998) had also investigated the relation between support at work and bullying. The trust employees were the participants of this survey. Measures included a 20 item inventory of bullying behaviors designed for the study, the job induced stress scale, the hospital anxiety and depression scale, the overall job satisfaction scale, the support at work scale, and the propensity to leave scale. $38 \%$ of staff in a community NHS trust reported being subjected to bullying behaviors in the workplace in the previous year and $42 \%$ had witnessed the bullying of others Staff who had been bullied had lower levels of job satisfaction.

\section{Statement of the Problem}

Workplace bullies create a tremendous liability for the employer by causing stress-related health and safety problems, and driving good employees out of the organization. The study is related to the factors that affect the employee stress level and their productivity through workplace bullying activity taken place in the organization.

The study have related the consequences of stress level among employees of an organization may lead to alienation from their work, loss of self-confidence, general irritability and bad temper, hyper sensitivity to criticism, workfamily conflict, frequent forgetfulness, inability to concentrate, loss of sense of humour, excessive aggressiveness and withdrawal into a number of definite strategies.

The reduction in the performance of employees in an organization and failure to effectively carrying out the responsibility vested in them would result in disastrous towards their work. Hence, it is mandatory to understand the 
causes of workplace bulling and how does it increase the stress level of the employees. This will help the employees in the organization to understand the negative effects of workplace bullying. This study helps to identify the employee's stress level caused by workplace bullying. This study will help the company to reduce its attrition rate due to workplace bullying.

\section{Objectives of the Study}

\subsection{Primary Objectives}

To find out the factors influencing workplace bullying and its impact on employee stress at a Private Company in Chennai.

\subsection{Secondary Objectives}

* To identify the impact of demographic variables on workplace bullying.

* To study the influence of personality traits on bullying of employees at workplace.

* To find out the relationship between workplace bullying and employee stress.

* To identify the various measures to be undertaken to reduce workplace bullying and to overcome the employee stress.

\section{Research Methodology}

Research methodology is a way to systematically solve the research problem. It may be understood as a science of studying how research is done scientifically. In this we study the various steps that are generally adopted by researcher in studying his research problem along with logic behind them.

\subsection{Research design}

A Research design is the specification of method and procedure for acquiring the information needed to structure or to solve problem. It is the overall operational pattern of frame work of the project that stipulates procedures. A research design is there defined as" A plan, structure and strategy of investigation conceived so as to obtain answers to research question and control variance.

\subsection{Descriptive research design}

Descriptive study is a fact finding investigation with adequate interpretation. Descriptive research design is concerned with the research studies with a focus on the portrayal of the characteristics of a group or individual or a situation.

Descriptive research, also known as statistical research, describes data and characteristics about the population or phenomenon being studied. Descriptive research answers the questions who, what, where, and how. Although the data description is factual, accurate and systematic, the research cannot describe what caused a situation.

\subsection{Sample}

Sampling may be defined as the selection of some part of an aggregate (or) totality on the basis of which a judgment (or) inference about the aggregate (or) totality is made.

\subsubsection{Sampling plan}

\subsubsection{Sample unit}

The sample universe (or) population for our study is the employees at an manufacturing company in Chennai.

\subsubsection{Sample Size}

The sample of 210 respondents was chosen from an manufacturing company in Chennai. 


\subsubsection{Sample Size Determination}

A pilot study is a small-scale methodological test intended to ensure that proposed methods and procedures will work in practice before being applied in a large, expensive investigation. The 25 samples to pre-test and check for the reliability of the questionnaire and also to determine a sample size of 210 from a larger population.

\section{Determination of sample size $=n=\frac{Z^{2} p q}{e^{2}}$}

$P$ - Probability of success

$q$ - Probability of failure.

$\mathrm{E}=$ Error rate.

$Z=$ value of normal distribution for the confidence level.

Here $z=1.96$ for $95 \%$ confidence limit and $E=0.05$

In our study,

The Probability of success $(p)=21 / 25=0.84$

The Probability of failure $(q)=4 / 25=0.16$

The sample size $=\boldsymbol{n}=\frac{Z^{2} p q}{\boldsymbol{e}^{2}}=\frac{(1.96)^{2}\left(\frac{21}{25}\right)\left(\frac{4}{25}\right)}{(0.05)^{2}}=\frac{3.8416 \times 0.1344}{0.0025}=\frac{0.5163}{0.0025}=210$ Samples

Therefore the samples that we are going to take for the study are 210samples.

\subsection{Sampling Techniques}

There are two types of sampling techniques they are Probability sampling and Non - probability sampling. The study makes use of the Probability sampling.

\subsubsection{Probability sampling}

When elements in the population have a known chance of being chosen as subjects in the sample, we resort to a probability sampling design.

\subsubsection{Stratified random sampling}

Populations are sub divided into sub populations or sub groups (strata). The approach by which this decision is made is named as stratified sampling. The process follows the following steps. After dividing population into subgroups, a simple random sample can be taken out from each subgroup and there after results can be combined according to population.

\subsection{Data collection}

\subsubsection{Primary data}

These are the actual information which is received by the resolution from the actual field of research. It is the data which has been collected by the researcher for a specific purpose using questionnaires.

\subsubsection{Questionnaire}

Questionnaire given to the respondents was structured undisguised questionnaire. The questions included dichotomous question, question including the use of ranking questions and open ended questions.

\subsubsection{Types of questions}

1. Closed ended question: Yes/No Questions and Multiple Choice Questions.

2. Open ended questions 


\subsubsection{Chart}

Charts can usually be read more quickly than the given data that they produced from. They are used in a wide variety of field, and can be created by hand (often on graph paper) (or) by computer using a charting application.

* A bar chart is a chart with rectangular bars with lengths proportional to the values that they represent. The bars can be plotted vertically (or) horizontally.

* A pie chart shows percentage value as a slice of pie.

\subsubsection{Secondary Data}

Secondary data are available generally from published and unpublished materials. The researcher collected data from the available books, journals, magazines, newspaper and also relevant websites and company website.

\subsection{Tools for analysis}

The following are some of the tools used in analysing the data.

* Percentage analysis

* Chi - square test of independence of attribute

* Interval estimation

* Correlation Analysis

* Weighted Average Method

* Mann-Whitney U-test

* Kruskal-Wallis H-test

\section{Limitation of the Study}

* The study conducted only in the Chennai branch. Findings are based on the views of only 210 respondents in the organisation.

* The study may not be absolute, accurate as the sample size is small. Information collected may be biased. The study was concentrated only with the available resources. It was difficult in approaching the respondents during the working hours and explaining the concept.

\section{Findings}

* $33 \%$ of the respondents feel that electrical department have more workplace bullying.

- $34.7 \%$ of the respondents have felt that workplace bullying is more in the age group below 25 years in their organisation.

* $42.4 \%$ of the respondents felt that they are criticized in their organisation.

* More than half of the respondents have felt that they are undermining in front of others.

* Most of the respondents felt that there performance is affected.

* Majority of the respondents felt that the false concern is not raised over their performance.

- 46.2\% of the respondents have felt that they are treated differently from their colleagues.

* $32 \%$ of the respondents have reported overloading of work in order to achieve targets in their organisation.

* $29.5 \%$ of the respondents have reported that their responsibility increases and as well as authority removed.

* Most of the respondents have felt that verbal threats are taken place in their organisation.

* $39 \%$ of the respondents are receiving their instruction directly through seniors.

* $32.9 \%$ of the respondents have agreed with the influences of workplace bullying towards employee stress.

* $36.7 \%$ of the respondents have felt over the pressure to meet the expectation.

* $62.8 \%$ of the respondents have felt on control of workplace bullying will reduces the employee stress.

* More of the respondents said that listening music is the measures that adopted to overcome the employees stress in their organisation.

* Most of the respondents prefer increasing in staff turnover is the factor that based on employee stress.

* $43.8 \%$ of the respondents have felt that productivity increases due to the control of workplace bullying in their organisation. 
* $42.4 \%$ of the respondents have felt that refusal to communicate is being followed to ignore an employee.

* Most of the respondents prefer willingness to compromise is the way to reduce work stress in their organisation.

* $32.8 \%$ of the respondents prefer to proper orientation procedure is the way to overcome the employee stress in their organisation.

* Most of the respondents feel that excessive control over the employee by the manager is the organisation factor that causes work stress in their organisation.

\section{Suggestion}

* The organisation may tell and concentrate on clear role clarity of the employees in their present position. They should provide a measure to overcome the verbal threat that taken place in between the employees.

* The organisation should suggest other measures to control the workplace bullying activity that taken place among the employees. The organisation may motivate the employees to participate on company activities to overcome from stress of employees.

* The organisation may continue to accept the employees' ideas, suggestion and feelings to motivate them to do the best in their job which can reduces the stress level of employees. The organisation should overcome the causes of workplace bullying \& decreases the employee stress level by making the employee's compromise in their job/work.

* The most of the respondents are expect that the management must have various measures to overcome employee stress and workplace bullying that taken place in electrical department. Developing anti bullying policies will make good business sense. Complaints against bullying can be investigated quickly and it is important to understand fully any incidence of bullying and take the problem seriously at all levels. The organisation should take care of every employee and their well-beings.

\section{Conclusion}

From the current study it is found that in the recent years bullying at workplace has increased to a greater extent. Due to this workplace bullying there is an increase in stress level of the employees in an organization. By taking proper measures against workplace bullying in an organization there is a wide opportunity to develop the welfare of the employees and to improve the harmony among the employees which in turn will increase the performance level of the employees. That workplace bullying and employee stress must be overridden by taking necessary action taken from the management for the employee productivity. Due to workplace bullying the stress level of employees both the work stress and individual stress has been affected. Management should concentrate and should make some necessary change in their existing workplace bullying activity which can help the employees in reducing their job stress in the organization. Management should take necessary measures to reduce workplace bullying and employee stress level. Employee stress level will be reduced due to control of workplace bullying activities taken place in the organization.

\section{References}

Andy Ellis (1994), "Bullying in the Workplace - An acceptable cost?" Project, Ruskin College, Oxford, UK.

Anni Townend (2005), "Understanding and addressing bullying in the workplace" Emerald Group Publishing Limited, Industrial and Commercial Training, Vol. 40, pp. 270-273.

C.R. Kotari, (2004), "Research Methodology Methods and Techniques", Second revised Edition, New Age International Publishers.

Jacqueline A. Gilbert et al. (2013), "Gender, Conflict, and Workplace Bullying: Is Civility Policy the Silver Bullet" Journal of Managerial Issues Vol. XXV Number 1 spring 2013: 79-98.

Judith MacIntosh et al. (2011), "How workplace bullying changes how women promote their health" Emerald Group Publishing Limited, International Journal of Workplace Health Management Vol. 4 No. 1, 2011pp. 48-66.

Kivimäki et al. (2002), "Research finds stress doubles heart risk" LRD Publications Ltd, Bargaining Report 232.

Rasool, Faheem et al. (1996), "Workplace Bullying and Intention to Leave: The Moderating Effect of the Organizational Commitment" Information Management and Business Review 5.4 (Apr 2013): 175-180.

Sheehan (1999), "Workplace bullying: responding with some emotional intelligence", International Journal of Manpower 20.1/2 (1999): 57-69.

Steven H. Appelbaum et al. (2012), "Workplace bullying: consequences, causes and controls" Emerald Group Publishing Limited, Industrial And Commercial Training, Vol. 44 No. 4 
Vartia, M. and Hyyti, J. (2002), "Gender differences in workplace bullying among prison officers", European Journal of Work and Organizational Psychology, Vol. 11 No. 1, pp. 113-26.

Vartia, M. (1996), "The sources of bullying: psychological work environment and organizational climate", European Journal of Work and Organizational Psychology, Vol. 5 No. 2, pp. 215-37.

\section{Web Link}

http://en.wikipedia.org/wiki/Bullying. 